\title{
Perceptions of risk: understanding cardiovascular disease
}

This article was published in the following Dove Press journal:

Risk Management and Healthcare Policy

4 September 2010

Number of times this article has been viewed

\author{
Ruth Webster ${ }^{1}$ \\ Emma Heeley ${ }^{2}$ \\ 'Cardiovascular Division, \\ ${ }^{2}$ Neurological and Mental Health \\ Division, The George Institute for \\ International Health, Camperdown, \\ NSW, Australia
}

\begin{abstract}
Cardiovascular disease (CVD) is still the leading cause of death and disability worldwide despite the availability of well-established and effective preventive options. Accurate perception of a patient's risk by both the patient and the doctors is important as this is one of the components that determine health-related behavior. Doctors tend to not use cardiovascular (CV) risk calculators and underestimate the absolute CV risk of their patients. Patients show optimistic bias when considering their own risk and consistently underestimate it. Poor patient health literacy and numeracy must be considered when thinking about this problem. Patients must possess a reasonably high level of understanding of numerical processes when doctors discuss risk, a level that is not possessed by large numbers of the population. In order to overcome this barrier, doctors need to utilize various tools including the appropriate use of visual aids to accurately communicate risk with their patients. Any intervention has been shown to be better than nothing in improving health understanding. The simple process of repeatedly conveying risk information to a patient has been shown to improve accuracy of risk perception. Doctors need to take responsibility for the accurate assessment and effective communication of $\mathrm{CV}$ risk in their patients in order to improve patient uptake of cardioprotective lifestyle choices and preventive medications.
\end{abstract}

Keywords: risk perception, cardiovascular disease, cardioprotective lifestyle

\section{Introduction}

Cardiovascular disease (CVD) is the leading cause of death and disability worldwide. ${ }^{1}$ The primary causative factors of CVD are well-known: $80 \%$ of acute myocardial infarctions can be attributed to just five modifiable risk factors, smoking, dyslipidemia, hypertension, diabetes, and obesity, ${ }^{2}$ which are also implicated in the increased risk of stroke. ${ }^{3}$ Data from the Framingham Heart Study clearly shows that these CVD risk factors do not simply act in isolation. ${ }^{4}$ In fact, they act synergistically such that minor abnormalities in several risk factors combine to produce a high absolute risk of disease. It is increasingly being recognized that the management of an individual's risk factors should be based on their overall or "absolute" risk of experiencing a CV event rather than on their levels of each risk factor. ${ }^{5}$ Many tools are now available to estimate an individual's 5- or 10-year risk of coronary disease or CVD, ${ }^{4,6,7}$ with most guidelines for prevention of CVD advising the assessment of absolute risk as a key step in managing risk. ${ }^{8-10}$

Once risk has been assessed, treatment options are established. Diet and exercise, ${ }^{11-13}$ smoking cessation, ${ }^{14,15}$ statin therapy, ${ }^{16}$ blood-pressure-lowering medication, ${ }^{17}$ and antiplatelet medications ${ }^{18}$ have all shown clear benefit in lowering CV risk. Despite 
there being a clear understanding of how to measure and subsequently modify CV risk, risk factors are highly prevalent in the general population ${ }^{19}$ and those who are indicated for pharmacological treatment are not necessarily receiving it. ${ }^{20-22}$ Within the broad range of factors that affect uptake of information and implementation of change, it is important to consider the role of doctors and patients in the perception of CV risk. Do doctors know how to accurately assess their patients' CVD risk? Do they communicate this risk to the patient? Does the patient understand his or her risk and its implications? What is the best way to communicate risk to a patient in order to maximize the likelihood of the patient understanding that information and acting on it?

This paper reviews and synthesizes the literature around doctors' ability to determine a patient's risk and the factors related to communication of that risk that may influence the patient's understanding of the risk. It also looks at the factors that influence patients' perception of their CV risk and how accurately patients understand their risk of CVD. Finally, we will discuss the evidence surrounding the most effective strategies to communicate risk with patients in order to maximize the potential impact of such strategies.

\section{Do doctors understand how to accurately assess a patient's risk?}

There is now extensive evidence regarding key risk factors for CVD and the importance of assessing a patient's absolute $\mathrm{CV}$ risk. International guidelines now recommend the incorporation of absolute CV risk assessment when assessing and treating risk factors. Many tools are now available to estimate an individual's 5- or 10-year absolute risk of coronary disease or CVD. ${ }^{4,6,7}$ However, this information is useful only if it is understood by doctors and then communicated accurately and effectively to patients.

Studies have shown suboptimal use of such tools in primary practice, varying from $17 \%$ to $47 \%{ }^{23-26}$ One qualitative study in Australia demonstrated that general practitioners (GPs) do not routinely perform absolute CVD risk assessments, and when they did, it was primarily for education purposes. ${ }^{27}$ The barriers to effective absolute CVD risk assessment identified from the study included lack of understanding of the difference between absolute and relative risk, poor understanding of how to use CVD risk tools in clinical management, and lack of incorporation of risk tools in practice software. Although some studies show that when doctors do use CV risk assessment tools they are not always used correctly, ${ }^{28}$ other research has shown high levels of accuracy. ${ }^{29}$
If GPs are not using risk assessment tools to estimate CV risk, how accurate are their estimations? Studies assessing the concordance between GPs assessment of CV risk and actual patients' CV risk found that the tendency is for GPs to underestimate the patient's risk. ${ }^{20,30-32}$ When case reports were used instead of actual patients, both overestimation and underestimation were seen with more tendency toward overestimation. ${ }^{33-38}$ Little research has been conducted on the accuracy of specialists' assessment of CV risk; however, in one study, when cardiologists were shown the same case reports as the GPs the former were more accurate regarding CVD risk but still tended to overestimate risk. ${ }^{33}$ Another study showed little difference in accuracy between GPs, cardiologists, and obstetricians/gynecologists. ${ }^{38}$

\section{Do doctors discuss CV risk with their patients?}

Several studies report that the general population primarily receives their information regarding CVD risk from the media. ${ }^{39-41}$ Media sources of risk, however, can provide only general information about a person's risk. Individualized advice about risk should come from a physician; in most cases, this will be the patient's GP. If this is the case, it is essential that GPs not only take the opportunity to discuss CVD risk when they can but also give accurate advice and present it in a way that the patient understands. Australian studies have shown that $80 \%$ of the population visits their doctor in a year, thereby providing an ideal opportunity for GPs to discuss CV risk with their patients. ${ }^{42}$

The barriers to effective estimation and communication of CVD risk by GPs have been identified as lack of time during the consultation, low patient level of education, and low physician level of skill in communicating. ${ }^{43,44}$

\section{Why is patients' perception of CVD risk important?}

\section{Theories surrounding health-related behavior}

Ideally, in order to prevent CVD, all you would need to do is present the general population with information relating to their risk of developing CVD including relevant risk factors followed by proven risk-factor-reduction strategies. Once given this information, an individual would look at it in a rational and logical manner and implement the discussed risk reduction strategies, thus minimizing his or her CVD risk. However, it is immediately apparent that this very rarely happens in reality. The factors that 
influence how individuals understand information and use that information to make decisions are many, and the decision pathway is complex. Multiple theories have been developed to try and explain how people make decisions, particularly those related to risk. Ultimately, it is unlikely that one theory will explain all decision-making behavior due to the complexity of human behavior; however, exploration of some decision-making theories can be helpful in understanding why patients do not always make the apparent best health-related choices with regard to both prevention and treatment. It is also possible to see where perception of risk fits into the decision-making pathway with regard to heath-related behavior.

\section{Health belief model}

The health belief model (HBM) ${ }^{45}$ was originally developed in the 1950s to explain "the widespread failure of people to accept disease preventives or screening tests for the early detection of asymptomatic disease". It identifies two components that behavior depends on: (1) the desire to avoid illness (or if ill, to get well) and (2) the belief that a specific heath action will prevent (or ameliorate) illness. The HBM consists of four dimensions:

1. Perceived susceptibility (the subjective perception of risk or vulnerability to a health threat)

2. Perceived severity (an individual's perception of the seriousness of the threat involved)

3. Perceived benefits (efficacy of an action designed to prevent or reduce the threat of an illness)

4. Perceived barriers (assessment of the negative consequences of undertaking the preventive action)

Also included is the requirement for a "cue to action" to start the process that may be internal, eg, symptoms, or external, eg, media coverage of a specific disease. It is recognized that diverse demographic, sociopsychological, and other variables may influence the individuals' perception and thereby indirectly influence health-related behavior. Research has shown that among the aforementioned dimensions, perceived barriers most frequently influences health-related behavior, followed by perceived susceptibility, benefits, and severity. Other factors are also recognized as contributing to decisions regarding health-related behavior such as habitual influences, health-related behaviors followed for nonhealth reasons (such as dieting to appear more attractive), and also economic and environmental factors. This model relies on the underlying belief that "health" is a valued commodity and that cues to action are prevalent in everyday life. The susceptibility and severity components mobilize the individual to act, whereas the perceived benefits and barriers are used to select a preferred course of action. This model tends to view decision making regarding health-related behavior as a cognitive process weighing risks and benefits, and does not specifically incorporate the impact of feelings on the decision-making process; rather, it views feelings as arising from the decisions that are made.

\section{Protection motivation theory}

The protection motivation theory $(\mathrm{PMT})^{46}$ is similar to HBM in that it places emphasis on cognitive processes mediating attitudinal and behavioral change. This theory, however, emphasizes that knowledge of an effective behavior is not sufficient, the individual must perceive themselves as being able to carry it out. This is seen as unrelated to and independent of the perceived barriers dimension of the HBM and provides the impetus to not only initiate a certain behavior but also influence the amount of energy expended and persistence despite obstacles. The PMT was developed to explain the effects of fear on attitude change. It postulates that fear influences attitude and behavior change not directly but indirectly by affecting a person's belief in the severity of the threat.

Briefly, PMT suggests that external information such as environmental cues or intrapersonal information stimulates the individual to initiate a threat appraisal and a coping appraisal. The threat appraisal evaluates factors that may increase or decrease the likelihood of initiating a certain action such as rewards for the behavior (eg, bodily pleasure) vs perceived severity of the threat and perceived vulnerability of the threat. A coping appraisal involves judgments about the efficacy of a preventive response, the perceived ability of one to successfully initiate and complete the adaptive response and the response costs (eg, inconvenience, expense, side effects). The combination of the threat appraisal and the coping appraisal forms the protection motivation, which then either stimulates or inhibits action. Protection motivation is maximized when:

1. The threat to the individual's health is severe.

2. The individual feels vulnerable.

3. The adaptive response is believed to be an effective means of averting the threat.

4. The person is confident he or she can successfully complete the adaptive response.

5. Rewards of maladaptive behavior are small.

6. Costs associated with adaptive behavior are small.

Research in PMT has shown support for the components of severity and vulnerability (resulting in behavioral 
intention to, eg, stop smoking or join an exercise program) as well as response efficacy and self-efficacy (causing predicted changes in intentions to engage in self-protective health behaviors). ${ }^{46}$

\section{Risk as feelings}

An alternative approach to models around health-related behavior hypothesizes that response to risk results from direct emotional influences. ${ }^{47,48}$ Action is determined by the interplay between cognitive evaluation and feelings at the time of decision making, with influence acting in both directions. Personal experience also weighs heavily on decisions under this model of thought. High levels of fear regarding an outcome may lead to defensive avoidance of an action rather than embracing the prospect of preventing the outcome. It is this emotional influence that may account for behavioral responses that do not coincide with an individual's best perceived course of action. Furthermore, fear responses tend to be unaffected by changes in probability. One determinant of emotional reactions to future outcomes is the vividness with which an individual mentally perceives the outcome. Other factors that influence reactions include an inverse relationship between the time, between the decision and the realization of the outcome, and the fear associated with the outcome. The effect of an individual's emotional situation at the time of decision making increases in influence as time for analysis decreases. ${ }^{48}$

Also of importance in this theory is the idea that patients base judgments of an activity not only on what they think about it but also on how they feel about it. This means feelings direct the judgment of risk and benefit. If they feel favorably about an activity then they are likely to judge the risks as low and the benefits as high, and vice versa.

\section{Unrealistic optimism}

Despite the different theories surrounding the determinants of health-related behavior, each theory incorporates at some point the concept of the individual's perception of his or her personal risk related to an activity or a disease state. It drives decision making as one of the determinants or is modified by or influences feelings. In this context, it is important to determine whether patients are realistic about their risk perception associated with particular conditions as this will contribute to the likelihood of patients adopting appropriate behaviors to reduce their risk.

Weinstein's work in the 1980s introduced the concept of most peoples" "unrealistic optimism" related to their vulnerability to a range of health issues. ${ }^{49-51}$ Weinstein interviewed college students regarding their perceived vulnerability to a wide range of health issues compared to their peers. ${ }^{49}$ Optimistic bias was defined as the majority of students indicating that the students considered themselves to be at a lower risk of developing a certain health issue compared to one of their peers. They showed a significant optimistic bias related to their risk for most health issues with the amount of bias varying greatly. Unrealistic optimism increased with perceived controllability of the issue or if they perceived an issue as something that would have already developed in them if it was going to affect them. Interest in taking steps to decrease their risk were correlated with worry, recognition of risk factors for the condition, perceived seriousness of the condition, mental image of the condition, heritability of the condition and environment. Weinstein concluded that the data collected was consistent with the belief of general population being concerned with "self-esteem enhancement", ie, we believe that we are inherently healthier than others or that our self-protective actions are more extensive or effective than those of others. Patients also tend to give themselves credit for self-protective factors in their life but fail to give similar credit to actions or behaviors associated with higher risk. Subjects in his study were also more realistic about factors that were unlikely to harm their self-esteem, eg, hereditary or environmental factors. The impact of this "optimistic bias" was that it reduced the motivation to take precautions to avoid the risk.

In order to expand the generalizability of his research, Weinstein further surveyed 296 members of the general community about their perceived health risks. ${ }^{51} \mathrm{He}$ found that optimistic bias was not limited to any particular age, sex, educational, or occupational group. He also confirmed that this tendency to optimistic bias increased with perceived preventability of the condition, perceived embarrassment associated with the condition, and belief of exemption if the condition had not already appeared. Decreased optimistic bias was associated with experience with the health condition, and the perceived frequency and the perceived extent of others in the community worrying about it.

Regarding CVD, Weinstein's work around the concept of optimistic bias predicts that majority of the population is unrealistic about their CVD risk.

\section{Patients' perception of their CVD risk General population}

Several studies have investigated the correlation between patients' perceived risk of CVD and their actual calculated 
risk based on epidemiological data. It appears that patients are generally inaccurate in their estimates and the bias tends to be toward inappropriate optimism. This has been confirmed in many different populations and by both qualitative and quantitative research.

Three studies have shown that about $40 \%$ of the general population underestimates their $\mathrm{CV}$ risk, ${ }^{52-54}$ with approximately $20 \%$ overestimating their risk. Although van der Weijden ${ }^{55}$ showed similar results for overestimation of risk (18\%), she found that only $15 \%$ underestimated their risk. The reason for this discrepancy in risk underestimation was unclear.

Interestingly, the study by Christian et al ${ }^{56}$ showed slightly different results with $71 \%$ of mainly ethnic women at medium-high risk of CVD having an accurate understanding of their risk but only $52 \%$ of low-risk women accurately identifying their low-risk status (ie, 29\% underestimating and $48 \%$ overestimating their risk). The study by Frijling ${ }^{57}$ showed similar results with $68 \%$ of patients overestimating their risk for a heart attack and 30\% underestimating their risk; results were similar for stroke. In Frijling's study, hypertensive or diabetic patients were asked to place their estimated risk on a numerical gauge from $0 \%$ to $100 \%$, compared to most other studies that used Likert scales for estimating relative risk. Interviews with "blue-collar" workers ${ }^{41}$ revealed that although some saw risk factors as influencing risk, others saw it as "luck of the draw". The behaviors shown to be effective in reducing risk were found to be in direct competition with those perceived as enhancing the quality of life, thus impacting the likelihood of patients adopting such activities.

\section{Risk awareness in women}

Mosca and colleagues have undertaken significant research into American women's awareness of CV risk, barriers to understanding risk, and implementation of preventive activities. A total of five cross-sectional surveys were conducted between 1997 and 2009 39,58-61 on women older than 25 years who answered questions regarding their awareness, knowledge, and perceptions of CVD risk and prevention.

In the 2009 survey, ${ }^{39} 54 \%$ of women correctly identified heart disease as the main cause of death in women, which had increased from 30\% in 1997. This 54\% included a tripling of awareness in black women and a doubling in white and Hispanic women although ethnic minorities were still less aware than white women. About $45 \%$ of surveyed women considered themselves to be well-informed about heart disease. Although 56\% cited chest, neck, shoulder, and arm pain as a symptom of heart disease, a considerably lesser number (7\%-29\%) identified less well-known symptoms such as shortness of breath, chest tightness, nausea, and fatigue. Only 53\% said they would call an ambulance if they thought they were having a heart attack; $25 \%$ would take an aspirin. Top prevention strategies were listed as getting adequate sleep, regular fish oil/omega-3 fatty acids, and taking aspirin. A matter of concern was that $60 \%-70 \%$ of women thought that taking antioxidants or special vitamins (eg, A, C, E) would help prevent heart disease. While 45\% cited television as their main source of information, $32 \%$ cited magazines, $18 \%$ the newspaper, and $14 \%$ the Internet. Of the women surveyed, $48 \%$ reported discussing heart disease with their doctor. The majority of women had taken some preventive actions in the previous year such as checking their blood pressure (84\%), trying to manage stress better (74\%), and going to see a doctor or other health professional (73\%). Reported barriers to taking preventive action included family/ care-giving responsibilities (51\%) and too much confusion in the media about what to do $(42 \%)$. The main motivators for taking preventive action were reported as wanting to improve their health, and feel better or live longer.

These cross-sectional studies give an insight into progress related to the effects of education regarding heart disease in the US. Despite mass media campaigns and widespread information dissemination, the majority of American women do not understand heart disease in much detail; there is also a lack of understanding of important preventive strategies. These findings are likely to be applicable to other countries as a National Heart Foundation of Australia cross-sectional survey of 3,500 Australians in the year 2009 reported that only around $20 \%$ of women knew that CVD was the leading cause of mortality for women and that they felt more threatened by breast cancer, despite the fact that mortality from heart disease is 4 times higher (personal written communication, June 9th, 2010). In contrast to men, women are more likely to consider factors such as stress as significant risk factors $^{62}$ and they see themselves at risk only after reaching menopause. ${ }^{63}$

\section{High-risk populations}

Estimation of risk has also been studied in selected populations with established high risk of CVD. In a population-based study of 1,253 patients at high risk of stroke, only $41 \%$ were aware of their increased stroke risk (only $42 \%$ of those who had already had a stroke were aware of their increased risk for a subsequent stroke). ${ }^{64}$ It was found that 79 patients discharged following treatment for heart attack 
showed no correlation between their perceived risk of another heart attack and their TIMI scores (a measure of risk post heart attack). ${ }^{65}$ A small study of 20 patients with diabetes showed that only 7 considered diabetes as a risk factor for CVD. ${ }^{66}$ Strecher et al ${ }^{67}$ evaluated whether smokers had a more realistic perception of their CVD risk than nonsmokers and found that although smokers were more likely to perceive themselves as at a higher risk of heart attack and stroke, they were still more likely than nonsmokers to have optimistic bias.

Since it is has been suggested that having obvious CVD risk factors does not necessarily improve an individual's estimation of risk, it is worth taking a look at what influences how patients think about their risk and what factors have been shown to be associated with an inaccurate estimation of risk.

\section{Why don't patients have an accurate understanding of their risk? General factors}

Patients generally have insufficient knowledge about CVD or CV risk factors ${ }^{55,68}$ and often tend to have a dichotomous understanding of risk rather than understanding risk as a continuum. They also tend to compare themselves to patients who are worse off than themselves when judging their personal risk rather than another average person like themselves.

Older age ${ }^{52,57,69}$ smoking, ${ }^{52,55,57,67,70}$ family history, ${ }^{52,53,57,69}$ the presence of typical CV risk factors, ${ }^{52,53,69}$ including obesity $^{53,55,70}$ and high blood pressure, ${ }^{55,69}$ and higher education level ${ }^{52}$ have all been shown to increase a person's perceived risk of CVD, which is likely to decrease the occurrence of optimistic bias. When accuracy of estimation of risk was specifically tested, older age, ${ }^{56,64}$ smoking, ${ }^{54}$ male sex, ${ }^{57-67}$ the presence of typical CV risk factors, ${ }^{64}$ including obesity ${ }^{54}$ and high blood pressure, ${ }^{54}$ and higher education level were all shown to increase the accuracy of estimated risk. ${ }^{54,67}$

Interestingly, other studies have shown that older age ${ }^{40,54,67}$ and male sex ${ }^{40,54,55}$ have in fact led to a decreased accuracy in estimation of risk.

In qualitative studies asking patients about what they perceive to be the most important risk factors for CVD, stress, ${ }^{41,66,71}$ smoking, ${ }^{41,53}$ and family history ${ }^{53,66,71}$ recurred as common themes rather than cholesterol and blood pressure. This has important implications when it comes to communicating risk to patients as doctors may discuss cholesterol and blood pressure even though the patient does not consider these issues to be particularly important when it comes to $\mathrm{CV}$ risk.

\section{Health literacy and numeracy}

Increasingly, it is recognized that in order to understand health-related information, patients must have a certain level of health literacy and numeracy.

Health literacy can been defined as "a constellation of skills, including the ability to perform basic reading and numerical tasks required to function in the health care environment" ${ }^{72}$ It has three levels: ${ }^{73}$

1. Basic/functional literacy (ie, basic reading and writing skills enabling a person to function effectively in everyday situations)

2. Communicative/interactive literacy (more advanced cognitive and literary skills that can be used to actively extract information, derive meaning from different forms of communication, and apply this meaning to changing circumstances)

3. Critical literacy (more advanced skills that can be used to critically analyze information and to exert greater control over life events and situation)

A key component of health literacy is numeracy, which in its broadest sense is the ability to understand and use numbers. Within this definition, however, are included more complex concepts such as the ability to perform simple arithmetic operations; compare magnitudes; and understand ratio concepts including fractions, proportions, percentages, and probabilities. ${ }^{74} \mathrm{~A}$ person's level of health literacy impacts many facets of health care including reading and understanding health literature, understanding medication labels and instructions, and keeping track of appointments. Level of numeracy is even more essential in the context of accurate risk perception as this requires the ability to assess risk magnitude, compare risks, and understand decimals, fractions, percentages, probabilities, and frequencies. ${ }^{74}$ Poor health literacy and numeracy is widespread but often not recognized. The proportion of patients with limited health literacy has been shown to be between $34 \%$ and $59 \%$ (primarily US data) ${ }^{75}$ with low numeracy shown to be associated with self-reported poor health, health disparities, poor health knowledge, poor disease self-management skills, and choice of lower-quality health options. ${ }^{76}$ The financial costs associated with low health literacy have been estimated as $3 \%-5 \%$ of total health costs. $^{75}$

One reason why poor health literacy impacts patients' understanding of CVD is that it has been shown that historically 
education material related to CVD is written at an inappropriate reading level. ${ }^{77}$ Most medical professionals rely on written materials to supplement their own education strategies in order to maximize the amount of information that can be given to patients; however, if those patients do not understand the literature and are too embarrassed to admit this (as is likely), there is no point handing the information out. Unfortunately, studies have shown that not only do physicians not understand the issue of health literacy or the level at which information needs to be given but they are also very poor at judging the health literacy or the numeracy ability of their patients. ${ }^{77}$ This lack of awareness and therefore lack of addressing the issue adds an extra layer of complexity to the reasons surrounding patients' poor perception of their CVD risk.

In the year 2005, the national cholesterol education program, an initiative of the National Heart, Lung, and Blood Institute (NHLBI) in the US, launched their national cholesterol education month with the slogan, "know your cholesterol numbers, know your risk". Considering the low numeracy identified in the US, it is unsurprising that this slogan was not recognized or found to be compelling by focus groups. ${ }^{55,68}$

\section{What strategies are recommended to maximize the chances of communicating risk effectively to patients?}

If accurate perception of risk by both patients and doctors is necessary in order to maximize the chance of the patient taking appropriate actions to reduce their risk, then it is important to recognize what strategies are most likely to improve perception of risk. However, it is also important to recognize the potential of information being manipulated using these strategies in order to coerce patients into adopting the physician's preferred course of action rather than help the patient decide within their own value system and life situation their preferred course of action. The intention is to aid the patient and the doctor to accurately understand the risk and not to manipulate their decision to suit a third party. Physicians should be aware framing is one such tool that may have the aforementioned effect.

\section{The effect of framing}

When options are presented to a patient for most health-related actions, several reviews have confirmed that patients are more likely to take up a recommended action when the benefits are presented as relative risk reduction (RRR) compared to absolute risk reduction (ARR) or number needed to treat
(NNT). ${ }^{78-80}$ It is possible that this is due to patients not comprehending the difference between a relative change and an absolute change. The larger apparent benefit communicated in RRR may be more attractive than the smaller apparent benefit discussed in ARR and NNT. This difference, however, is modified in studies where baseline risk information was given and it has been considered that some of the larger differences seen may be due to methodological problems in the studies where it was not made clear in the intervention whether the risk reduction was absolute or relative (eg, is the statement "death was reduced by $20 \%$ in the intervention group" referring to an ARR or RRR?).

Similarly, when discussing screening, patients tend to be more responsive when the disadvantages of not being screened (loss framing) rather than the advantages of being screened are discussed. ${ }^{79}$

Physicians have also been shown to be affected by framing of information with the same responses shown by patients. When results are shown as RRR, rather than ARR or NNT, physicians are more likely to treat a patient. This was sometimes modified or nullified by risk aversion, physician experience, level and type of risk, clinical situation, beliefs about treatment efficacy, and costs of treatment. ${ }^{81}$ A limiting factor in this research is that studies have been carried out using scenarios and hence the effect on clinical practice is unknown.

One example of this concept in practice is as follows: pharmaceutical companies, when advertising their products, tend to use RRR as their method of communication. Although ARR or NNT may be included in the original research, the marketing information will almost always mention RRR. These companies are obviously aware that research has shown more people respond to RRR than other forms of risk communication. This is particularly relevant in countries where pharmaceutical companies are allowed to market directly to the consumer (such as the US); patients may then approach their doctor demanding treatment that may not be indicated, recommended, or as beneficial as the patient believes. If the doctor also does not fully understand the statistics presented by such companies then patients may end up inappropriately treated.

Incomplete understanding of RRR vs ARR or NNT can be used to manipulate behavior by deliberately utilizing one statistic over another without providing all the information necessary to make a balanced decision. This can affect the decisions of both doctors and patients as both groups have been shown to be affected by framing. Deliberately utilizing this type of manipulation in the doctor-patient relationship could be seen as nullifying the "informed consent" 
part of treatment discussion although some may argue that a paternalistic attitude in presenting information is justified when the patient's best interests are central to the motivation.

\section{Fear appeals}

Communicating information in a way that instills fear in the recipient can be highly effective in convincing a person to do something or not do something. ${ }^{82}$ This principle has been used in many health-related advertising campaigns, particularly those aimed at smoking and the use of sunscreen. Fear appeals have been shown to motivate attitude, intention, and behavior changes especially when accompanied by high-efficacy messages, and therefore they can be useful to doctors. ${ }^{82}$ However, this approach can backfire if the person hearing the message does not believe they can effectively avert the threat; in these cases, it can lead to a defensive denial response. ${ }^{82}$

\section{General evidence-based tools for communicating evidence}

Any communication tool is better than nothing for improving knowledge about health care. ${ }^{83}$ The more structured, tailored, and interactive the method of communicating evidence, the greater the resulting level of knowledge and understanding in patients. Training for health care professionals in patient-centered approaches has also been shown to be effective in increasing the patient's level of understanding the evidence.

Decision aids (any intervention designed to help patients make specific and deliberative choices among options by providing information on the options and the outcomes relevant to a person's health status and implicit methods to clarify values) have been shown to result in: ${ }^{84}$

1. Greater knowledge

2. Lower decisional conflict related to feeling uninformed

3. Lower decisional conflict related to feeling unclear about personal values

4. Reduced proportion of patients who were passive in decision making

5. Reduced proportion of patients who remained undecided postintervention

6. More accurate risk perception (if probabilities were included in the decision aid) with better accuracy if the probabilities were presented quantitatively rather than qualitatively

\section{Communication of risk}

A recent systematic review showed that repeatedly providing patients with global coronary heart disease (CHD) risk education alone or with accompanying education increased the patient's accuracy of risk perception and probably increased intent to start therapy. Studies utilizing this type of intervention showed small significant reductions in predicted CHD risk (absolute differences of $-0.2 \%$ to $2 \%$ older than 10 years). ${ }^{85}$

Generally, when communicating risk, it is recommended to use simple numbers (not log scales) with clear explanations where there is no requirement for the patient to perform their own calculations. ${ }^{86}$ Patients have a more accurate perception of risk when it is communicated in numerical rather than descriptive (such as "a small chance", "not very likely", "very likely") format. ${ }^{83,84,87}$ When using numerical format, it is important to be consistent with the type of statistic being used (ie, percentage, natural frequencies, relative risk) and also the denominator so that the patient can compare apples with apples. ${ }^{86-88}$ When presenting relative risk, patients are likely to overestimate the risk and therefore a baseline value needs to be provided as well to provide a reference point. ${ }^{83,86}$ When presenting information, it is also important to provide an interpretative standard or threshold, if possible, in order to aid understanding (eg, above/below average) and also to personalize the risk to the individual. ${ }^{86}$

Use of visual aids such as graphs, icons, and illustrations can be helpful in increasing the understanding of a particular concept. ${ }^{83,86,87}$ Large amounts of data can be summarized in a graph or other type of figure, but it must be remembered that some graphs can be highly complex or confusing and therefore can lead to confusion in the patient. ${ }^{86}$ It is important to use the appropriate graph for a specific purpose and always provide clear, comprehensible explanations of the graph. The downside of graphs or other visual cues can be that they may be more time consuming to prepare, particularly in the case of an individual's CVD risk. Availability of CVD risk calculators built into practice software is widespread in developed countries; however, this may be an issue elsewhere.

Communicating other specific characteristics of risk such as multiplicative risk, cumulative risk, and also small probabilities requires more specific strategies; however, little research has been done on the optimal way to communicate such characteristics. ${ }^{86}$

In addition to the practical aspects of how to enable a patient to understand the numbers associated with their CVD risk, it is also important that the patient trust the doctor; otherwise, patients are unlikely to believe what the doctors are saying or take action based on their recommendations. ${ }^{87,89}$ Paling ${ }^{87}$ suggests that striving for both competence and a caring approach in the consultation is imperative to instilling trust in a patient. 
One novel strategy that was developed to try and overcome the problem of low health literacy in the general population was a primer that aimed at improving patients' medical data interpretation skills..$^{90}$ It was written in a language suitable for patients aged 14 years or younger, and in randomized trials conducted in both low and high socioeconomic groups it improved medical interpretation scores and also interest in medical statistics. Participants in the trials rated the primer highly and spent quite a bit of time reading it although this did not increase the patients' confidence in interpreting statistics outside the primer. However, this type of intervention is essential in attempting to overcome the significant hurdle of low health literacy and numeracy.

\section{Patient preferences for type of visual aid}

Few qualitative studies have been conducted that aim at eliciting patients' preferred format for receiving risk information. Graphical formats (particularly bar charts) have been perceived as helpful in some studies but not in others ${ }^{68,91}$ (Hill, unpublished data). Thermometer scales, with percentages and strong use of color to demonstrate comparative risk, were also preferred in one study (Hill, unpublished data). Two studies showed a preference for risk to be presented in absolute terms rather than relative risk. ${ }^{68,91}$

\section{Internet}

Delivery of health information via computer has also been shown to increase efficacy, ${ }^{92}$ Widespread community access to the Internet ${ }^{93}$ and the increasing use of the Internet as a source of information related to health ${ }^{94}$ provides a novel opportunity for low-cost, Internet-based, community-mediated health care delivery. Previous studies have shown that highly interactive health communications applications that allow multiple interactions with participants over time may have a positive effect on knowledge sharing and social support with some evidence of improved behavioral and clinical outcomes in patients with chronic diseases. ${ }^{95}$ There is also some evidence that such applications can positively influence behaviors related to $\mathrm{CV}$ risk such as nutrition and physical activity. ${ }^{96}$

In the field of $\mathrm{CV}$ prevention, the provision of tailored behavior change messages has been shown to enhance uptake of information compared to simple provision of health risk information, ${ }^{97}$ and there exist some websites offering such tailored advice directed at the consumer. ${ }^{98,99}$ Unfortunately, these websites tend to be simple, without the highly interactive features that have been shown to be effective in changing behavior. To make available a cheap, simple webpage that provides consumers with information is unlikely to make a serious impact on patients' CVD risk prevention practices. What is needed is investment in high-quality, easily accessible, highly interactive websites containing tailored advice specific to a patient.

\section{Improving doctors' assessment of CVD risk}

Underlying the aforementioned recommendations for enhancing patients' understanding of their risk is the necessity for health care professionals to understand how to calculate absolute risk and change their practice to routinely calculate absolute CVD risk for their patients. Systematic review of strategies to improve doctors' utilization of CVD risk tables showed no clear relationship between any particular strategy and the uptake of CVD risk tables; however, promising strategies seemed to be those involving teamwork, nurse-led clinics, and integrated information technology (IT) support (eg, computerized decision support). Recommendations included the need to support physicians in identifying highrisk patients (possibly through integrated computerized decision support or invitation letters to patients in their practice to attend for review), completing the risk profile (this could be achieved via an integrated computerized decision support tool), calculating the risk (in order to address the documented failure of many physicians to accurately use these risk calculators), communicating risk (possibly by increased education regarding communication strategies), and deciding jointly with the patient on appropriate management of their risk.

Such a computerized decision support tool that populates itself with data from the patient's electronic record, calculates CVD risk, and presents the doctor with specific treatment advice based on current guidelines has been developed in Australia. ${ }^{100}$ Widespread availability of such a tool has the potential to address many of the identified barriers to accurate perception of CVD risk by doctors.

\section{Conclusion}

In most cases, CVD is a preventable disease. However, the opportunity to prevent it is not being taken up by large numbers of patients. Accuracy of patients' perception of the level of their CVD risk is essential in the prevention of CVD (especially for those at the highest risk level) as it will help stimulate the adoption of preventive actions and activities. Many factors contribute to a person's understanding of his or her CVD risk. Accuracy of information given to patients and their ability to understand that information are important, but individuals are also influenced by social context, emotional state, and other lifestyle factors such as work or 
caring responsibilities. Anecdotal experience from a person's family or social group cannot be underestimated either. ${ }^{41}$

Generally, patients do not have an accurate idea of their CVD risk and unfortunately this predominantly results in underestimation of risk. A matter of perhaps more concern is that GPs, who are perfectly positioned to provide information to patients and correct their misperceptions about CVD prevention, are also likely to underestimate the patients risk resulting in missed opportunities to educate patients, treat CVD, and ultimately prevent CVD. In order to correct patients' understanding of their risk, the accuracy of doctors' understanding of CVD risk needs to be improved and they need to be educated further in proven effective means to communicate risk to their patients.

Advancement in understanding the role of CVD risk, the multiplicative nature of risk factors, and how to calculate a person's CVD risk has overtaken many GPs' knowledge in this area. The GPs need to comprehend the extent of low numeracy and literacy in the population and take this into consideration when providing health-related information. Further education is required to remedy this issue both at a medical school level and the level of those already established in practice. Aids to help GPs must take into account short consultation times because often attention on a patient's CVD risk will need to be opportunistic and dealt with at the end of a consultation related to another medical problem.

Further research is needed specifically in the area of communicating CVD risk, including development of standardized tools that have been shown to be effective not only in communicating risk but also in changing practice that GPs can use to communicate with their patients. Regular training opportunities will aid in upskilling to enhance accurate communication of risk.

Development of novel strategies such as electronic decision support tools linked to electronic health records may help GPs in calculating risk and provide them with visual tools such as graphs to help in communicating this risk to patients.

Although CVD is preventable, it can be prevented only if patients have an accurate perception of their risk of CVD. It is the responsibility of doctors and other health professionals to continue to work to bridge this gap.

\section{Disclosure}

The authors report no conflicts of interest in this work.

\section{References}

1. Murray CJL, LopezAD. The Global Burden of Disease: A comprehensive assessment of mortality and disability from diseases, injuries, and risk factors in 1990 and projected to 2020. Boston, MA: Harvard School of Public Health; 1996.
2. Yusuf S, Hawken S, Ounpuu S, et al. Effect of potentially modifiable risk factors associated with myocardial infarction in 52 countries (the INTERHEART study): case-control study. Lancet. 2004;364:937-952.

3. Sacco RL, Benjamin EJ, Broderick JP, et al. Risk factors. Stroke. 1997;28(7):1507-1517.

4. Anderson KM, Odell PM, Wilson PW, et al. Cardiovascular disease risk profiles. Am Heart J. 1991;121(1 Pt 2):293-298.

5. Jackson R, Lawes CMM, Bennett DA, et al. Treatment with drugs to lower blood pressure and blood cholesterol based on an individual's absolute cardiovascular risk. Lancet. 2005;365(9457): 434-441.

6. British Cardiac S, British Hyperlipidaemia A, British Hypertension S, et al. Joint British recommendations on prevention of coronary heart disease in clinical practice: summary. Br Med J. 2000;320(7236): 705-708.

7. Jackson R. Updated New Zealand cardiovascular disease risk-benefit prediction guide. Br Med J. 2005;320:709-710.

8. Graham I, Atar D, Borch-Johnsen K, et al. European guidelines on cardiovascular disease prevention in clinical practice: full text: Fourth Joint Task Force of the European Society of Cardiology and other Societies on Cardiovascular Disease Prevention in Clinical Practice (constituted by representatives of nine societies and by invited experts). Eur J Cardiovasc Prev Rehabil. 2007;14:S1.

9. National Vascular Disease Prevention Alliance. Guidelines for the assessment of absolute cardiovascular disease risk, 2009. Available from: http:// www.nhmrc.gov.au/publications/index.htm. Accessed July 27, 2010.

10. Pearson TA, Blair SN, Daniels SR, et al. AHA guidelines for primary prevention of cardiovascular disease and stroke: 2002 update: consensus panel guide to comprehensive risk reduction for adult patients without coronary or other atherosclerotic vascular diseases. Circulation. 2002;106(3):388-391.

11. Ness AR, Powles JW. Fruit and vegetables, and cardiovascular disease: a review. Int J Epidemiol. 1997;26(1):1-13.

12. Parikh P, McDaniel MC, Ashen MD, et al. Diets and cardiovascular disease: an evidence-based assessment. J Am Coll Cardiol. 2005;45(9):1379-1387.

13. Thompson PD, Buchner D, Pina IL, et al. Exercise and physical activity in the prevention and treatment of atherosclerotic cardiovascular disease: a statement from the Council on Clinical Cardiology (Subcommittee on Exercise, Rehabilitation, and Prevention) and the Council on Nutrition, Physical Activity, and Metabolism (Subcommittee on Physical Activity). Circulation. 2003;107(24):3109-3116.

14. Kawachi I, Colditz GA, Stampfer MJ, et al. Smoking cessation and time course of decreased risks of coronary heart disease in middle-aged women. Arch Intern Med. 1994;154(2): $169-175$.

15. Woodward M, Lam TH, Barzi F, et al. Smoking, quitting, and the risk of cardiovascular disease among women and men in the Asia-Pacific region. Int J Epidemiol. 2005;34(5):1036-1045.

16. Baigent C, Keech A, Kearney PM, et al. Efficacy and safety of cholesterol-lowering treatment: prospective meta-analysis of data from 90,056 participants in 14 randomised trials of statins. Lancet. 2005;366(9493):1267-1278.

17. Turnbull F, Blood Pressure Lowering Treatment Trialists C. Effects of different blood-pressure-lowering regimens on major cardiovascular events: results of prospectively-designed overviews of randomised trials. Lancet. 2003;362(9395):1527-1535.

18. Antithrombotic Trialists' Collaboration. Collaborative meta-analysis of randomised trials of antiplatelet therapy for prevention of death, myocardial infarction, and stroke in high risk patients. $\mathrm{Br} \mathrm{Med} J$. 2002;324:71-86.

19. Mackay J, Mensah G. Atlas of Heart Disease and Stroke. Geneva, Switzerland: World Health Organization; 2004.

20. Heeley EL, Peiris DP, Patel AA, et al. Cardiovascular risk perception and evidence - practice gaps in Australian general practice (the AusHEART study). Med J Aust. 2010;192(5):254-259. 
21. Peiris DP, Patel AA, Cass A, et al. Cardiovascular disease risk management for Aboriginal and Torres Strait Islander peoples in primary health care settings: findings from the Kanyini Audit. Med J Aust 2009;191(6):304-309.

22. Webster RJ, Heeley EL, Peiris DP, et al. Gaps in cardiovascular disease risk management in Australian general practice. Med J Aust. 2009;191(6):324-329.

23. de Koning JS, Klazinga NS, Koudstaal PJ, et al. Quality of care in stroke prevention: results of an audit study among general practitioners. Prev Med. 2004;38(2):129-136.

24. de Muylder R, Lorant V, Paulus D, et al. Obstacles to cardiovascular prevention in general practice. Acta Cardiol. 2004;59(2):119-125.

25. Eaton CB, Galliher JM, McBride PE, et al. Family physician's knowledge, beliefs, and self-reported practice patterns regarding hyperlipidemia: a National Research Network (NRN) survey. J Am Board Fam Med. 2006;19(1):46-53.

26. Graham IM, Stewart M, Hertog MG. Factors impeding the implementation of cardiovascular prevention guidelines: findings from a survey conducted by the European Society of Cardiology. Eur J Cardiovasc Prev Rehabil. 2006;13(5):839-845.

27. Torley D, Zwar N, Comino EJ, et al. GPs' views of absolute cardiovascular risk and its role in primary prevention. Aust Fam Physician. 2005;34(6):503-504.

28. Peeters A, Ting J, Nelson MR, et al. Coronary heart disease risk prediction by general practitioners in Victoria. Med J Aust 2004; $180: 252$.

29. Isles CG, Ritchie LD, Murchie P, et al. Risk assessment in primary prevention of coronary heart disease: randomised comparison of three scoring methods. Br Med J. 2000;320(7236):690-691.

30. Cacoub P, Tocque-Le Gousse E, Fabry C, et al. Application in general practice of treatment guidelines for patients with dyslipidaemia: the RESPECT study. Arch Cardiovasc Dis. 2008;101(11-12):715-721.

31. McManus RJ, Mant J, Meulendijks CFM, et al. Comparison of estimates and calculations of risk of coronary heart disease by doctors and nurses using different calculation tools in general practice: cross sectional study. BMJ. 2002;324(7335):459-464.

32. Montgomery AA, Fahey T, MacKintosh C, et al. Estimation of cardiovascular risk in hypertensive patients in primary care. Br J Gen Pract. 2000;50(451):127-128.

33. Friedmann PD, Brett AS, Mayo-Smith MF. Differences in generalists' and cardiologists' perceptions of cardiovascular risk and the outcomes of preventive therapy in cardiovascular disease. Ann Intern Med. 1996;124(4):414-421.

34. Grover SA, Lowensteyn I, Esrey KL, et al. Do doctors accurately assess coronary risk in their patients? Preliminary results of the coronary health assessment study. BMJ. 1995;310(6985):975-978.

35. Meland E, Laerum E, Stensvold I. Assessment of coronary heart disease risk, I. A postal inquiry among primary care physicians. Fam Pract. 1994;11(2):117-121

36. Pignone M, Phillips CJ, Elasy TA, et al. Physicians' ability to predict the risk of coronary heart disease. BMC Health Serv Res. 2003;3(1):13.

37. Thomsen TF, Jørgensen T, Ibsen H, Borch-Johnsen K. Assessment of coronary risk in general practice in relation to the use of guidelines: a survey in Denmark. Prev Med. 2001;33(4):300-304.

38. Mosca L, Linfante AH, Benjamin EJ, et al. National study of physician awareness and adherence to cardiovascular disease prevention guidelines. Circulation. 2005;111(4):499-510.

39. Mosca L, Mochari-Greenberger H, Dolor RJ, et al. Twelve-year follow-up of American women's awareness of cardiovascular disease risk and barriers to heart health. Circ Cardiovasc Qual Outcomes. 2010;3(2):120-127.

40. Pancioli AM, Broderick J, Kothari R, et al. Public perception of stroke warning signs and knowledge of potential risk factors. JAMA. 1998;279(16):1288-1292.

41. Ritchie JE, Herscovitch F, Norfor JB. Beliefs of blue collar workers regarding coronary risk behaviours. Health Educ Res. 1994;9(1):95-103.
42. Knox SA, Harrison CM, Britt HC, et al. Estimating prevalence of common chronic morbidities in Australia. Med J Aust. 2008;189(2):66-70.

43. Doroodchi H, Abdolrasulnia M, Foster J, et al. Knowledge and attitudes of primary care physicians in the management of patients at risk for cardiovascular events. BMC Fam Pract. 2008;9(1):42.

44. van Steenkiste B, van der Weijden T, Stoffers HEJH, et al. Barriers to implementing cardiovascular risk tables in routine general practice. Scand J Prim Health Care. 2004;22(1):32-37.

45. Janz NK, Becker MH. The Health Belief Model: a decade later. Health Educ Q. 1984;11(1):1-47.

46. Prentice-Dunn S, Rogers RW. Protection motivation theory and preventive health: beyond the health belief model. Health Educ Res. 1986;1(3):153-161.

47. Loewenstein GF, Weber EU, Hsee CK, et al. Risk as feelings. Psychol Bull. 2001;127(2):267-286.

48. Slovic P, Finucane ML, Peters E, et al. Risk as analysis and risk as feelings: some thoughts about affect, reason, risk, and rationality. Risk Anal. 2004;24(2):311-322.

49. Weinstein ND. Unrealistic optimism about susceptibility to health problems. J Behav Med. 1982;5(4):441-460.

50. Weinstein ND. Why it won't happen to me: perceptions of risk factors and susceptibility. Health Psychol. 1984;3(5):431-457.

51. Weinstein ND. Unrealistic optimism about susceptibility to health problems: conclusions from a community-wide sample. J Behav Med. 1987;10(5):481-500.

52. Avis NE, Smith KW, McKinlay JB. Accuracy of perceptions of heart attack risk: what influences perceptions and can they be changed? Am J Public Health. 1989;79(12):1608-1612.

53. Marteau TM, Kinmonth AL, Pyke S, et al. Readiness for lifestyle advice: self-assessments of coronary risk prior to screening in the British family heart study. Family Heart Study Group. Br J Gen Pract. 1995;45(390):5-8

54. Niknian M, McKinlay SM, Rakowski W, et al. A comparison of perceived and objective CVD risk in a general population. Am J Public Health. 1989;79(12):1653-1654.

55. van der Weijden T, van Steenkiste B, Stoffers HE, Timmermans DR, Grol R. Primary prevention of cardiovascular diseases in general practice: mismatch between cardiovascular risk and patients' risk perceptions. Med Decis Making. 2007;27(6):754-761.

56. Christian AH, Mochari HY, Mosca LJ. Coronary heart disease in ethnically diverse women: risk perception and communication. Mayo Clin Proc. 2005;80(12):1593-1599.

57. Frijling BD, Lobo CM, Keus IM, et al. Perceptions of cardiovascular risk among patients with hypertension or diabetes. Patient Educ Couns. 2004;52(1):47-53.

58. Christian AH, Rosamond W, White AR, et al. Nine-year trends and racial and ethnic disparities in women's awareness of heart disease and stroke: an American Heart Association national study. $J$ Womens Health. 2007;16(1):68-81.

59. Mosca L, Ferris A, Fabunmi R, et al. Tracking women's awareness of heart disease: an American Heart Association national study. Circulation. 2004;109(5):573-579.

60. Mosca L, Jones WK, King KB, et al. Awareness, perception, and knowledge of heart disease risk and prevention among women in the United States. American Heart Association Women's Heart Disease and Stroke Campaign Task Force. Arch Fam Med. 2000;9(6): 506-515.

61. Robertson RM. Women and cardiovascular disease: the risks of misperception and the need for action. Circulation. 2001;103(19): 2318-2320.

62. Furze G, Lewin B. Causal attributions for angina: results of an interview study. Coronary Health Care. 2000;4(3):130-134.

63. Hart PL. Women's perceptions of coronary heart disease: an integrative review. J Cardiovasc Nurs. 2005;20(3):170-176.

64. Samsa GP, Cohen SJ, Goldstein LB, et al. Knowledge of risk among patients at increased risk for stroke. Stroke. 1997;28(5): 916-921. 
65. Broadbent E, Petrie KJ, Ellis CJ, et al. Patients with acute myocardial infarction have an inaccurate understanding of their risk of a future cardiac event. Intern Med J. 2006;36(10):643-647.

66. Carroll C, Naylor E, Marsden P, et al. How do people with Type 2 diabetes perceive and respond to cardiovascular risk? Diabet Med. 2003;20(5):355-360.

67. Strecher VJ, Kreuter MW, Kobrin SC. Do cigarette smokers have unrealistic perceptions of their heart attack, cancer, and stroke risks? J Behav Med. 1995;18(1):45-54.

68. Goldman RE, Parker DR, Eaton CB, et al. Patients' perceptions of cholesterol, cardiovascular disease risk, and risk communication strategies. Ann Fam Med. 2006;4(3):205.

69. Meischke H, Sellers DE, Robbins ML, et al. Factors that influence personal perceptions of the risk of an acute myocardial infarction. Behav Med. 2000;26(1):4-13.

70. Silagy C, Muir J, Coulter A, et al. Cardiovascular risk and attitudes to lifestyle: what do patients think?[see comment]. BMJ. 1993;306(6893):1657-1560.

71. Hunt K, Davison C, Emslie C, et al. Are perceptions of a family history of heart disease related to health-related attitudes and behaviour? Health Educ Res. 2000;15(2):131-143.

72. Ad Hoc Committee on Health Literacy for the Council on Scientific Affairs AMA. Health literacy: report of the Council on Scientific Affairs. Ad Hoc Committee on Health Literacy for the Council on Scientific Affairs, American Medical Association. JAMA. 1999;281(6):552-557.

73. Nutbeam D. Health literacy as a public health goal: a challenge for contemporary health education and communication strategies into the 21st century. Health Promot Int. 2000;15(3):259-267.

74. Reyna VF, Nelson WL, Han PK, et al. How numeracy influences risk comprehension and medical decision making. Psychol Bull. 2009;135(6):943-973

75. Eichler K, Wieser S, Brugger U. The costs of limited health literacy: a systematic review. Int J Public Health. 2009;54(5):313-324.

76. Nelson W, Reyna VF, Fagerlin A, et al. Clinical implications of numeracy: theory and practice. Ann Behav Med. 2008;35(3):261-274.

77. Safeer RS, Cooke CE, Keenan J. The impact of health literacy on cardiovascular disease. Vasc Health Risk Manag. 2006;2(4): 457-464.

78. Covey J. A Meta-analysis of the effects of presenting treatment benefits in different formats. Med Decis Making. 2007;27(5): 638-654.

79. Edwards A, Elwyn G, Covey J, et al. Presenting risk information - a review of the effects of framing and other manipulations on patient outcomes. J Health Commun. 2001;6(1):61-82.

80. Moxey A, O'Connell D, McGettigan P, et al. Describing treatment effects to patients. J Gen Intern Med. 2003;18(11):948-959.

81. McGettigan P, Sly K, O'Connell D, et al. The effects of information framing on the practices of physicians. JGIM. 1999;14:633-642.

82. Witte K, Allen M. A meta-analysis of fear appeals: implications for effective public health campaigns. Health Educ Behav. 2000;27(5):591-615.

83. Trevena LJ, Davey HM, Barratt A, et al. A systematic review on communicating with patients about evidence. J Eval Clin Pract. 2006;12(1):13-23.

Risk Management and Healthcare Policy

\section{Publish your work in this journal}

Risk Management and Healthcare Policy is an international, peerreviewed, open access journal focusing on all aspects of public health, policy, and preventative measures to promote good health and improve morbidity and mortality in the population. The journal welcomes submitted papers covering original research, basic science, clinical \& epidemio-
84. O'Connor AM, Bennett CL, Stacey D, et al. Decision aids for people facing health treatment or screening decisions. Cochrane Database Syst Rev. 2009(3):CD001431.

85. Sheridan SL, Viera AJ, Krantz MJ, et al. The effect of giving global coronary risk information to adults: a systematic review. Arch Intern Med. 2010;170(3):230-239.

86. Lipkus IM. Numeric, verbal, and visual formats of conveying health risks: suggested best practices and future recommendations. Med Decis Making. 2007;27(5):696-713.

87. Paling J. Strategies to help patients understand risks. BMJ. 2003;327(7417):745-748.

88. Gigerenzer G, Edwards A. Simple tools for understanding risks: from innumeracy to insight. BMJ. 2003;327:741-744.

89. Alaszewski A, Horlick-Jones T. How can doctors communicate information about risk more effectively? BMJ. 2003;327(7417):728-731.

90. Woloshin S, Schwartz LM, Welch HG. The effectiveness of a primer to help people understand risk: two randomized trials in distinct populations. Ann Intern Med. 2007;146(4):256-265.

91. Fortin J, Hirota L, Bond B, et al. Identifying patient preferences for communicating risk estimates: a descriptive pilot study. BMC Med Inform Decis Mak. 2001;1(1):2.

92. Portnoy DB, Scott-Sheldon LAJ, Johnson BT, et al. Computer-delivered interventions for health promotion and behavioral risk reduction: a meta-analysis of 75 randomized controlled trials, 1988-2007. Prev Med. 2008;47(1):3-16.

93. Burns E. Active Home Internet Users by Country, Sep 2008. Available from: http://www.clickz.com/3631547. Archived at: http://www. webcitation.org/5neJm5DJb. Accessed February 18, 2010.

94. Fox S. Online Health Search, 2006. Available from: http://www. pewinternet.org/PPF/r/190/report_display.asp. Archived at: http:// www.webcitation.org/5neJsA5Fk. Accessed February 18, 2010.

95. Murray E, Burns J, See TS, et al. Interactive Health Communication Applications for people with chronic disease. Cochrane Database Syst Rev. 2005(4):CD004274. Update of Cochrane Database Syst Rev. 2004;(4):CD004274.

96. Kroeze W, Werkman A, Brug J. A systematic review of randomized trials on the effectiveness of computer-tailored education on physical activity and dietary behaviors. Ann Behav Med. 2006;31(3):205-223.

97. Kreuter MW, Strecher VJ. Do tailored behavior change messages enhance the effectiveness of health risk appraisal? Results from a randomized trial. Health Educ Res. 1996;11(1):97-105.

98. Bennet M. A risk score for cardiovascular disease. 2005. Available from: http://www.riskscore.org.uk/. Archived at: http://www.webcita tion.org/5neJZ5ixW. Accessed February 18, 2010

99. Siteman Cancer Center. Your Disease Risk: the source on prevention. Available from: http://www.yourdiseaserisk.wustl.edu/. Archived at: http://www.webcitation.org/5neJc986X. Accessed February 18, 2010.

100. Peiris DP, Joshi R, Webster RJ, et al. An electronic clinical decision support tool to assist primary care providers in cardiovascular disease risk management: development and mixed methods evaluation. J Med Internet Res. 2009;11(4):e51.

logical studies, reviews and evaluations, guidelines, expert opinion and commentary, case reports and extended reports. The manuscript management system is completely online and includes a very quick and fair peerreview system, which is all easy to use. Visit http://www.dovepress.com/ testimonials.php to read real quotes from published authors. 